\title{
Review Article \\ Supercritical Algal Extracts: A Source of Biologically Active Compounds from Nature
}

\author{
Izabela Michalak, ${ }^{1}$ Agnieszka Dmytryk, ${ }^{1}$ Piotr P. Wieczorek, ${ }^{2}$ Edward Rój, ${ }^{3}$ \\ Bogusława Lęska, ${ }^{4}$ Bogusława Górka, ${ }^{2}$ Beata Messyasz, ${ }^{5}$ Jacek Lipok, ${ }^{2}$ \\ Marcin Mikulewicz, ${ }^{6}$ Radosław Wilk, ${ }^{1}$ Grzegorz Schroeder, ${ }^{4}$ and Katarzyna Chojnacka ${ }^{1}$ \\ ${ }^{1}$ Department of Advanced Material Technologies, Faculty of Chemistry, Wrocław University of Technology, \\ Smoluchowskiego 25, 50-372 Wrocław, Poland \\ ${ }^{2}$ Faculty of Chemistry, Opole University, Plac Kopernika 11, 45-040 Opole, Poland \\ ${ }^{3}$ Supercritical Extraction Department, New Chemical Syntheses Institute, Aleja Tysiąclecia Państwa Polskiego 13a, \\ 24-110 Puławy, Poland \\ ${ }^{4}$ Faculty of Chemistry, Adam Mickiewicz University in Poznań, Umultowska 89b, 61-614 Poznań, Poland \\ ${ }^{5}$ Department of Hydrobiology, Faculty of Biology, Adam Mickiewicz University in Poznań, Umultowska 89, 61-614 Poznań, Poland \\ ${ }^{6}$ Department of Dentofacial Orthopeadics and Orthodontics, Medical University of Wrocław, Krakowska 26, 50-425 Wrocław, Poland \\ Correspondence should be addressed to Izabela Michalak; izabela.michalak@pwr.wroc.pl
}

Received 9 May 2015; Accepted 28 June 2015

Academic Editor: Iciar Astiasaran

Copyright (C) 2015 Izabela Michalak et al. This is an open access article distributed under the Creative Commons Attribution License, which permits unrestricted use, distribution, and reproduction in any medium, provided the original work is properly cited.

\begin{abstract}
The paper discusses the potential applicability of the process of supercritical fluid extraction (SFE) in the production of algal extracts with the consideration of the process conditions and yields. State of the art in the research on solvent-free isolation of biologically active compounds from the biomass of algae was presented. Various aspects related with the properties of useful compounds found in cells of microalgae and macroalgae were discussed, including their potential applications as the natural components of plant protection products (biostimulants and bioregulators), dietary feed and food supplements, and pharmaceuticals. Analytical methods of determination of the natural compounds derived from algae were discussed. Algal extracts produced by SFE process enable obtaining a solvent-free concentrate of biologically active compounds; however, detailed economic analysis, as well as elaboration of products standardization procedures, is required in order to implement the products in the market.
\end{abstract}

\section{Introduction}

The increase of public awareness, concerning potentially harmful ingredients present in commercial products, put the pressure on manufacturers to apply natural, environmental friendly materials of improved quality. Such requirements are met by algal biomass, the capacity of which, despite long history in daily living products, still remains largely unexplored [1]. Algae, both micro- and macrocellular (seaweeds), are known as a rich source of bioactive compounds, including proteins, minerals, vitamins, polysaccharides, polyphenols, phlorotannins, pigments, unsaturated fatty acids, sterols, and phytohormones $[2,3]$. The properties of these compounds were used in various branches of industry, such as chemical, pharmaceutical, human food, and animal feed production and integrated systems of plant cultivation $[1,4]$.

Among possible ways of enriching a given product with algal-derived material, application of extract is the most frequently reported. In order to extract bioactive substances from raw biomass, the proper solvent (e.g., water and organic solvents) should be chosen. The application of conventional methods of extraction (extraction in Soxhlet apparatus, solidliquid extraction, and liquid-liquid extraction) has some disadvantages, for example, the use of high volumes of solvents and difficult medium separation [5]. Therefore, in the recent years, solvent-free methods of extraction have been developed. Alternatively to conventional procedures, supercritical 
fluid extraction is usually proposed. This technique fulfills the market demand for both high quality and chemically safe products [6]. The term "supercritical" corresponds to substance behavior after exceeding the value of both critical temperature and pressure (the so-called "critical point"). Supercritical fluid (SCF) shows features bordering on characteristics of gaseous and liquid form of the compound and might be classified somewhere between these two states. Thus, supercritical fluids have unusual capacity to extract selected constituents from complex material, the efficacy of which is worth researching $[7,8]$.

In a present work, a review of SFE condition requirements, technological aspects, and obstacles is presented, as well as the application prospects of supercritical extracts from algae. Special attention was paid to the use of algae based products in agriculture, as a rich source of natural plant growth stimulators. Another section was also devoted to the novel analytical methods which are necessary to examine the organic and inorganic composition of algal extracts. On the basis of the composition of the new product, potential applications are sought.

\section{Supercritical Fluid Extraction as an Efficient Method of Isolation of Valuable Compounds}

Solvation properties of supercritical fluids were reported for the first time in 1879 by Hannay and Hogarth [9]. The idea of involving supercritical fluid extraction in industrial technologies was shown in public in 1969 by Zosel [10]. Due to the global concern of environmental damage caused by large-scale use of organic solvents in classical extractions, the implementation of new technologies, using minimum volumes of solvents, became the subject of great interest [11]. Currently, a lot of attention is paid to optimize processes under supercritical conditions, so that they can be used more extensively. However, there are still economic and energy issues (e.g., high investment cost and labor-intensive step of sample processing) that limit the use of SFE in commercial productions [12].

2.1. Fundamentals of SFE. In the literature, supercritical fluid extraction is usually compared with conventional processes in order to present advantages and disadvantages of both methods. Absence of the harmful or toxic chemicals in the final product is the most evident advantage of SFE. Fluids under supercritical state surpass organic solvents in reducing process time and required amount of the sample by an order of magnitude and in enhancing the yield of extraction [13]. Such differences resulting from the complex nature of supercritical fluids, lower viscosity and surface tension with higher compressibility and diffusivity (gas- and liquid-like features, alternately) enable more effectively penetrating the material and hence provide better mass transfer between phases $[5,14]$. The high selectivity (ease of being modified by changing temperature or pressure value only, e.g., tuneable solvating power) and facility for fractionation of extracted compounds are also emphasized as the major benefits of using supercritical fluids. For industrial application of SFE, the exclusion of oxygen and low processing temperature (depended on the type of fluid) is worth mentioning, since it gives an opportunity to obtain volatile or labile constituents without their damage $[12,13,15]$.

A variety of compounds, both inorganic (carbon dioxide, nitrous oxide, ammonia, sulphur hexafluoride, and water) and organic (ethane, propane, $n$-pentane, fluoroform, and chlorodifluoromethane (Freon-22)) was subjected to tests under critical conditions [15]. Among examined fluids, supercritical $\mathrm{CO}_{2}\left(\mathrm{SC}-\mathrm{CO}_{2}\right)$ has been reported as the most common choice. Benefits of using SC- $\mathrm{CO}_{2}$ are well known and include such features as relatively low critical parameters $\left(T=31^{\circ} \mathrm{C}, p=73.8\right.$ bar), chemical inertness, no or low toxicity, nonflammability, noncorrosivity, and GRAS designation (Generally Recognized as Safe) from both American Food and Drug Administration and European Food Safety Authority $[5,15,16]$. Furthermore, under normal conditions, carbon dioxide is a gas, which can be easily separated from the extract and hence recovered, what reduces its cost [16]. Despite several advantages, $\mathrm{SC}-\mathrm{CO}_{2}$ is not a universal extractant, since it is nonpolar. Therefore, isolation of compounds with high polarity needs to be supported with modifiers, cosolvents, which if added at low concentration increase solvating power of the fluid towards the target compound [6]. In case of supercritical carbon dioxide, methanol and ethanol are the most frequently reported. The former is more efficient and the latter is less toxic $[6,11,13]$.

Extraction under supercritical fluid requires equipment which involves a tank of the mobile phase (chosen solvent), a pump to pressurize the fluid, an oven comprising the extraction vessel with a matrix, a restrictor to maintain the high pressure inside the system, and a trapping vessel. Extracts are trapped during decompression of the analytecontaining SCF into an empty vial, through a solvent, or onto a solid or liquid material. There are three possible ways of SFE: dynamic mode, static mode, or a combination mode. In the former, the fluid flows continuously through the sample (extraction vessel) and out of the restrictor to the trapping vessel. In static mode, the fluid circulates in a loop within the extraction vessel for some period before being released through the restrictor to the trapping vessel. In combination mode, a static extraction is performed for some period of time, followed by a dynamic extraction [17].

2.2. Parameters in SFE. Crampon et al. reviewed the parameters that have an impact on the kinetics and efficiency of extraction of microalgae and seaweeds carried out under supercritical conditions $\left(\mathrm{SC}-\mathrm{CO}_{2}\right)$ from dry biomass. Pressure seems to be the most important parameter [7]. At constant temperature, the higher the pressure, the higher the density and thereby enhanced yields and/or faster extraction kinetics might be noted $[7,15]$. In the case of temperature, its effect on the strength of supercritical fluid depends on the pressure (retrograde behavior). Correlation between these two parameters varies and is determined by pressure value called "crossover point," above which increasing temperature improves solvating power [15]. 
Another important parameter in SFE is solvating power (selectivity) of supercritical fluids. It increases with density. Such correlation was not observed for conventional liquid solvents. The density of extractant under supercritical conditions can be adjusted to the process needs by temperature, pressure, and/or composition (content of modifiers) [14, 18]. Efficiency of the extraction is also clearly related to molecular weight of analytes, their concentration in the sample, type and strength of binding to the matrix, and solubility in specific SFC. Considering extraction with supercritical carbon dioxide, it is advised to work with a high $\mathrm{SC}-\mathrm{CO}_{2}$ /algae mass ratio [19].

Selection of the proper values of process variables is crucial for obtaining high degree of extraction. Since there are several variables to change, optimization of SFE might be performed through various approaches, which are generally classified as phase equilibrium strategies and experimental design with statistical modeling. The first approach considers limitation of stages that influence the final effect of the process. The second approach complements this knowledge by fitting statistical treatment to the results [6].

2.3. Preparation of the Biomass for SFE. Applying supercritical fluids to treat biological materials, including algae, in a profitable way is highly dependent on the proper pretreatment. In the first step, the biomass undergoes centrifugation, after which the concentrated algal suspension should be subjected to a drying process, freeze-drying or drying at low temperatures. High sample moisture might lead to a few disadvantages, such as limitation of the matrix-SCF contact [20] or, in case of applying supercritical $\mathrm{CO}_{2}$, acidic hydrolysis of the analytes due to carbonic acid formation [21]. Therefore, there is a common practice to remove excess water during sample pretreatment. Finally, algae are crushed to break the cellular wall and thus increase extraction efficiency. Concerning the effect of crushing, results obtained by Crampon et al. indicated that the smaller the particle, the more rapid the kinetics of extraction and the higher the yields. Disintegration of cells is essential in the recovery of intracellular products from algae [7]. According to literature, the SFE can be coupled with cells disintegration techniques to obtain higher yields. Ultrasounds and microwaves are proved to facilitate extraction, hence the productivity, as well as reducing the time of the process [12]. Additionally, the following methods might be used: freezing, alkaline and organic solvents, osmotic shocks, sonication, homogenization at high pressure, and bead milling $[22,23]$. Moreover, in the study of Valderrama et al., cells of $H$. pluvialis and S. maxima were crushed by cutting mills (coffee mill) and manually ground with dry ice [2].

\section{Production of Algal Extracts by Supercritical Fluid Extraction}

3.1. Extraction of Biologically Active Compounds from Algae by SFE. Algae form a diverse group of micro- and macroorganisms (seaweeds) containing a great amount of biologically active compounds, which participate in processes of growth, development, and protection and therefore are considered to be capable of affecting other living organisms. The vast array of bioactive compounds in algae is the result of their adaptation to unfavorable environmental conditions. Production of these compounds increases when the environmental stress factors are occurring, for example, changes of temperature, salinity, drought stress, tidal flows, lack of nutrients, or presence of hostile organisms [24]. Algae are found in both marine and freshwater environments. Chemical composition of algae has not been known as well as terrestrial plants. On the other hand, algae contain unique compounds that are absent in higher plants [2,3].

Supercritical fluids were first used for treating algal matrix to select biomolecules valuable in food processing industry $[14,17]$. Currently, other functional compounds of proven activity on human health, plant growth, or livestock productivity and biofuels of new generation have been obtained from algae by using SFE [25-28].

Based on literature studies, microalgal cells are used in extraction with supercritical fluids more frequently than seaweeds. In the last 14 years, the words "supercritical fluid extraction and microalgae" appeared in the topic of the scientific papers 88 times, whereas "supercritical fluid extraction and seaweed" only 21 times (Web of Knowledge, December 12, 2014; http://apps.webofknowledge.com/). Adequate examples of applying supercritical conditions for microalgal biomass processing are collected in Table 1.

In the presented examples, $\mathrm{SC}-\mathrm{CO}_{2}$ was chosen as a solvent, occasionally supported by a modifier; ethanol and operational conditions ranged within $40-85^{\circ} \mathrm{C}$ and $78.6-500$ bar. In general, SFE was particularly used for the extraction of pigments, lipids including polyunsaturated fatty acids (PUFAs) (e.g., omega-3 fatty acids: eicosapentaenoic acid (EPA) and docosahexaenoic acid (DHA) and omega-6 fatty acid: $\gamma$-linolenic acid (GLA) and arachidonic acid (AA)), polyphenols, and vitamins [23].

As it was mentioned above, there are fewer reports on the production of supercritical seaweed extracts. Most research on producing supercritical extracts from macroalgae focuses on comparing solvating power of SCFs with organic extractants. Marine red macroalgae Hypnea charoides were investigated as a nonconventional source of $\omega-3$ fatty acids obtained by extraction with $\mathrm{SC}-\mathrm{CO}_{2}$. Tests were conducted under mild conditions: temperature range $40-50^{\circ} \mathrm{C}$ and pressure range 241-379 bar. Different conditions enabled observing their influence on product yield: the higher the temperature and pressure, the better the lipid recovery and ratio of unsaturated fatty acids. Moreover, solubility, hence extractability, of $\omega-3$ fatty acids in supercritical $\mathrm{CO}_{2}$ was proven to depend on the chain length [29]. SC- $\mathrm{CO}_{2}$ was also used to extract fucoxanthin from brown seaweed Undaria pinnatifida [30]. A broad range of operational conditions was applied: temperature $25-60^{\circ} \mathrm{C}$, pressure $200-400$ bar, and $\mathrm{CO}_{2}$ flow rate $1.0-4.0 \mathrm{~mL} / \mathrm{min}$, to investigate the variations of process efficiency. It was shown that the product recovery increased with decreasing temperature and increasing pressure and the highest yield of fucoxanthin (almost $80 \%$ ) was achieved at $40^{\circ} \mathrm{C}$ and 400 bar during 3-hour extraction. More examples of the application of SFE of algal biomass (both 


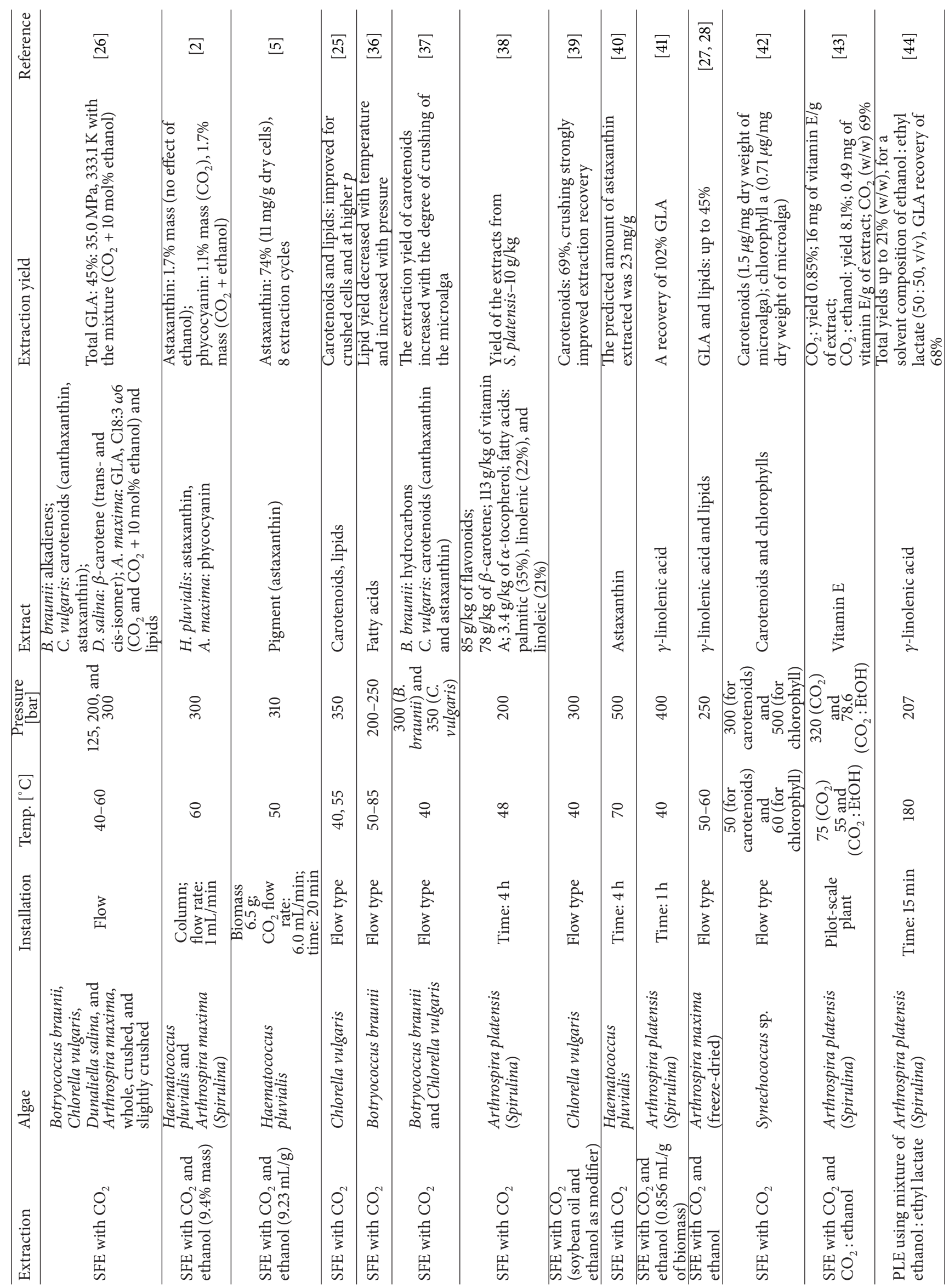


micro- and macroalgae) are presented in a review paper of Michalak and Chojnacka [23].

\subsection{Comparison SFE with Other Extraction Techniques from} Biomass of Algae. Despite regulations limiting the use of chemicals and proven efficacy of using supercritical fluids as extractants, conventional solvent extraction still remains the leading technique to provide algae derived compounds for cosmetic or food industry $[5,26]$. Applying organic solvents requires additional step of their recovery and posttreatment and might change physicochemical properties and functionality of isolated compounds [5]. There is an increasing number of reports focusing on comparison of conventional methods with SFE and some are summed in Table 2.

Halim et al. investigated a lab-scale biodiesel production by extracting lipids from green microalgae Chlorococcum sp. with the use of two different solvents: $\mathrm{SC}-\mathrm{CO}_{2}$ and $n$ hexane. Obtained results confirmed usability of supercritical conditions to algal lipid recovery. It was concluded that SFE generated comparable yield to Soxhlet extraction and shortened process time by over five times. Nevertheless, the time required to complete the extraction might be insufficient criterion [31]. In research of Crespo and Yusty, isolation of $n$-alkanes, C18, C19, C20, C22, C24, C28, C32, and C36, and the acyclic isoprenoid Pristane from brown seaweed Undaria pinnatifida was conducted by the use of $n$-hexane:dichloromethane mixture (Soxhlet mode) and SC$\mathrm{CO}_{2}$ with a modifier. Although SFE enabled hastening the process from days (conventional extraction) to 1 hour, the authors concluded that both methods are comparable, since the obtained yields of hydrocarbons were not significantly different. It was also noted that solvating power of $\mathrm{SC}-\mathrm{CO}_{2}$ is higher than organic solvent in case of longer-chain $n$ alkanes [32]. As opposed to investigation of Crespo and Yusty, supercritical $\mathrm{CO}_{2}$ (with and without cosolvent) in experiments on isolation of astaxanthin (AXA) and chlorophyll from microalgae Monoraphidium sp. GK12 was proved to surpass ethanol. Efficacy of using chosen solvents was verified by performing bead beater extraction (BBE), the results of which were established as $100 \%$. The yield of astaxanthin obtained by SFE was twice as high as in EtOH-extracts and this advantage increased with higher concentration of modifier to finally achieve similar level to the result of BBE. In case of extraction of chlorophyll, applying supercritical conditions was slightly more effective than both of the other methods [33]. Supercritical fluid extraction was also shown to be an efficient pretreatment method in the production of polysaccharides (fucoidan) from biomass of brown seaweeds Fucus evanescens, Saccharina japonica, and Sargassum oligocystum. It provided the equivalent yield as conventional (organic solvent) method [34].

3.3. General Application of Algae Derived Compounds. Extracted algal compounds are characterized by anticoagulant, anticancer, antiallergic, antiviral, antifungal, antioxidative, and immunomodulating activities [35]. These properties make that algal extracts have broad potential applications, for example, as components in cosmetics, medicines, pharmaceuticals, nutraceuticals, feed additives, nutrition (feed) and food additives, aquaculture, plant growth biostimulants and bioregulators, biofuels, and pollution prevention [23].

It should be underlined that some algal-origin molecules are assigned for specific species or taxonomic groups. For example, in cyanobacteria typical bioactive compounds are malyngolide (Lyngbya majuscula (Dillwyn) Harvey), nostodione (Nostoc commune Vaucher), cyanobacterin (Scytonema hofmanni Kütz., and Nostoc linckia (Roth) Bornet \& Flahault), aponin (Gomphosphaeria aponina Kütz.), fischerellin (Fischerella muscicola (Thuret) Gom.), and scytophycins (Scytonema pseudohofmanni Bharad.). It was shown that they demonstrate antibacterial, antifungal, and even antialgal properties that can be used in pharmaceutical industry [45]. In the work of Ramesh et al., the main attention was paid to active substances isolated from freshwater algae with pharmaceutical applications. This group of algae produces compounds with a vast array of properties: from antimicrobial and antiviral to cytotoxicity and immunomodulatory activity. Freshwater algae provide a diverse and unique source of bioactive compounds that can be used for the discovery of modern drugs (antibiotics, mycotoxins, alkaloids, and phenolic compounds) [46].

Another group of bioactive compounds constitute carotenoids ( $\beta$-carotene, astaxanthin, and canthaxanthin) and phycocyanin (water-soluble phycobiliprotein) isolated from algal biomass. They can be used as natural pigments in nutrition of animals and humans [2]. Algae are a promising commercial source of carotenoids due to the relative fast growth rate (especially microalgae). Some species, such as unicellular Dunaliella salina (Dunal) Teod. or Dunaliella bardawil Ben-Amotz \& Avron, demonstrate their capability to accumulate large amount of $\beta$-carotene in chloroplasts in the form of lipid globules. Adverse environmental conditions, such as high salinity, rapid change in temperature, and nutrient limitation acting as a stressor, may increase this capacity [47].

Other important compounds extracted from algae are unsaturated fatty acids [31, 48]. Fatty acid composition of marine algae species differs totally from higher plants. For example, cells of Arthrospira (Spirulina) maxima contain polyunsaturated $\gamma$-linolenic acid and $\alpha$-linolenic acid (ALA), which can be the component of pharmaceuticals (schizophrenia, multiple sclerosis, diabetes, and rheumatoid arthritis) [26]. Fatty acids produced from algae, linolenic acid (from Arthrospira sp.), arachidonic acid (Porphyridium sp.), eicosapentaenoic acid (Chlorella vulgaris Beij.), and docosahexaenoic acid (C. vulgaris), have high biological activity and are mainly used in nutritional supplements [49, 50].

The extraction of the mentioned biologically active compounds from algae by SFE is especially recommended because this technique protects them from thermal or chemical degradation. Active ingredients in solvent-free environments are particularly important for their applications in medicines and nutraceuticals [26]. The industrial importance is due to not only the algal extract but also the postextraction residue which can be used as animal feedstock [12]. Algal 


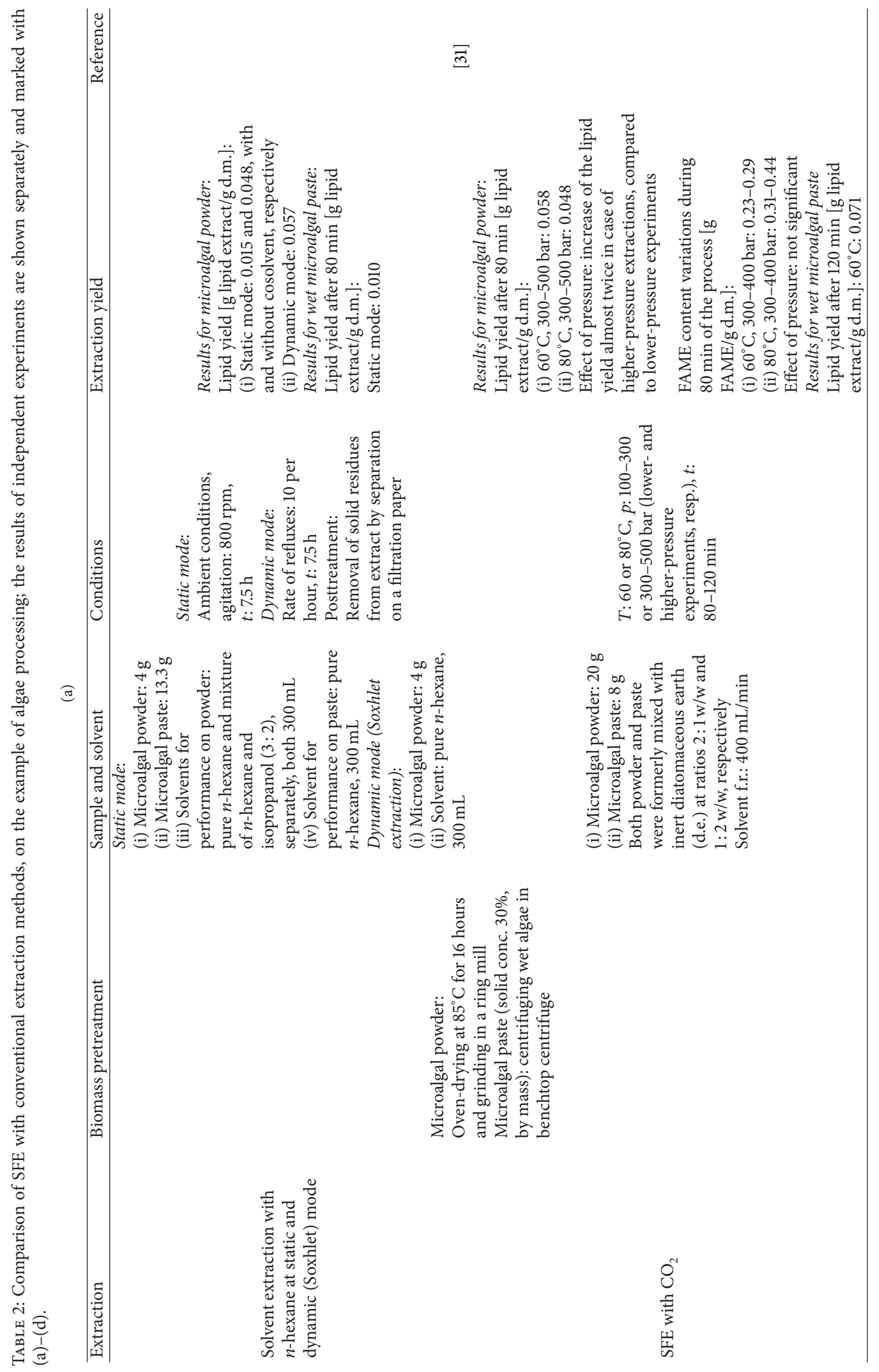




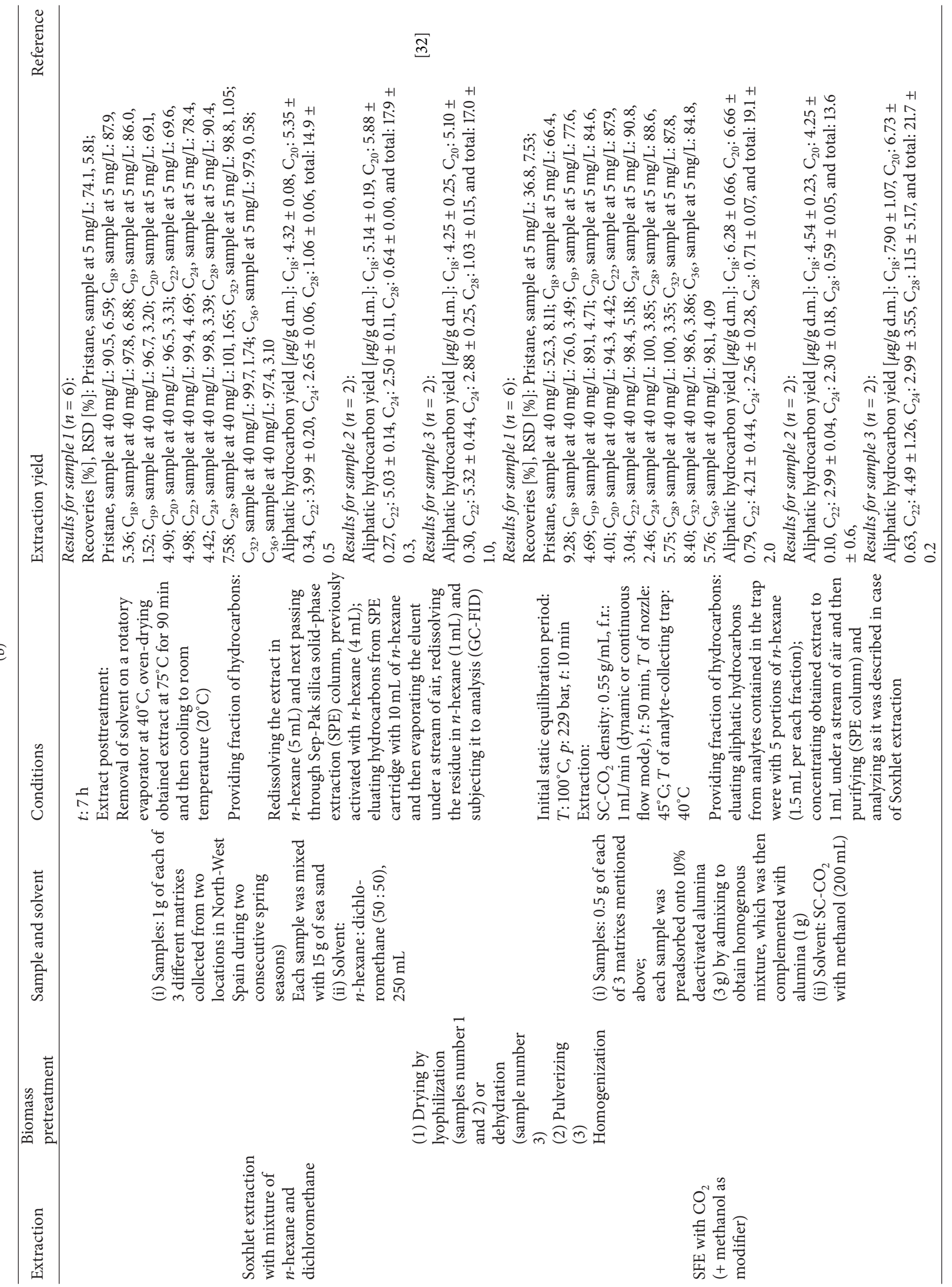




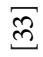

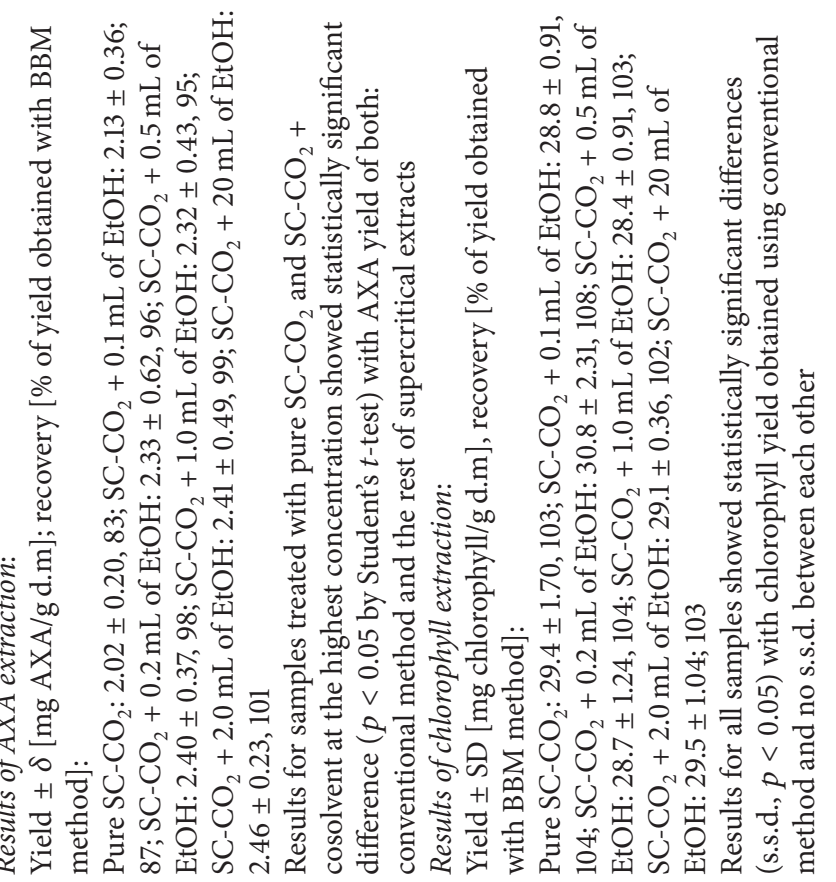

()

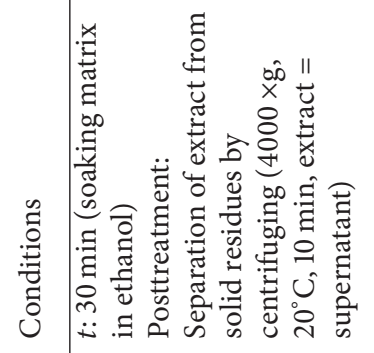

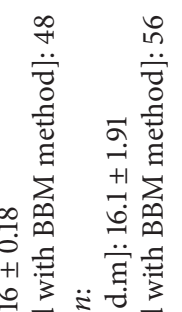

뭉

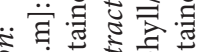

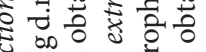

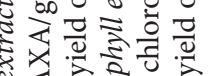

उ

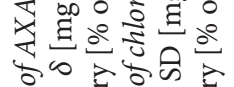

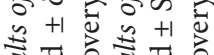

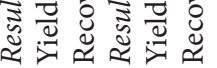

年

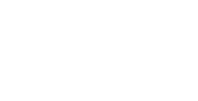

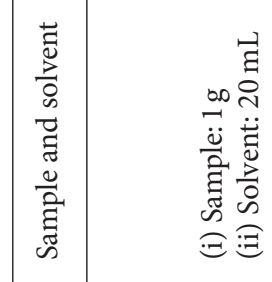

逆昱
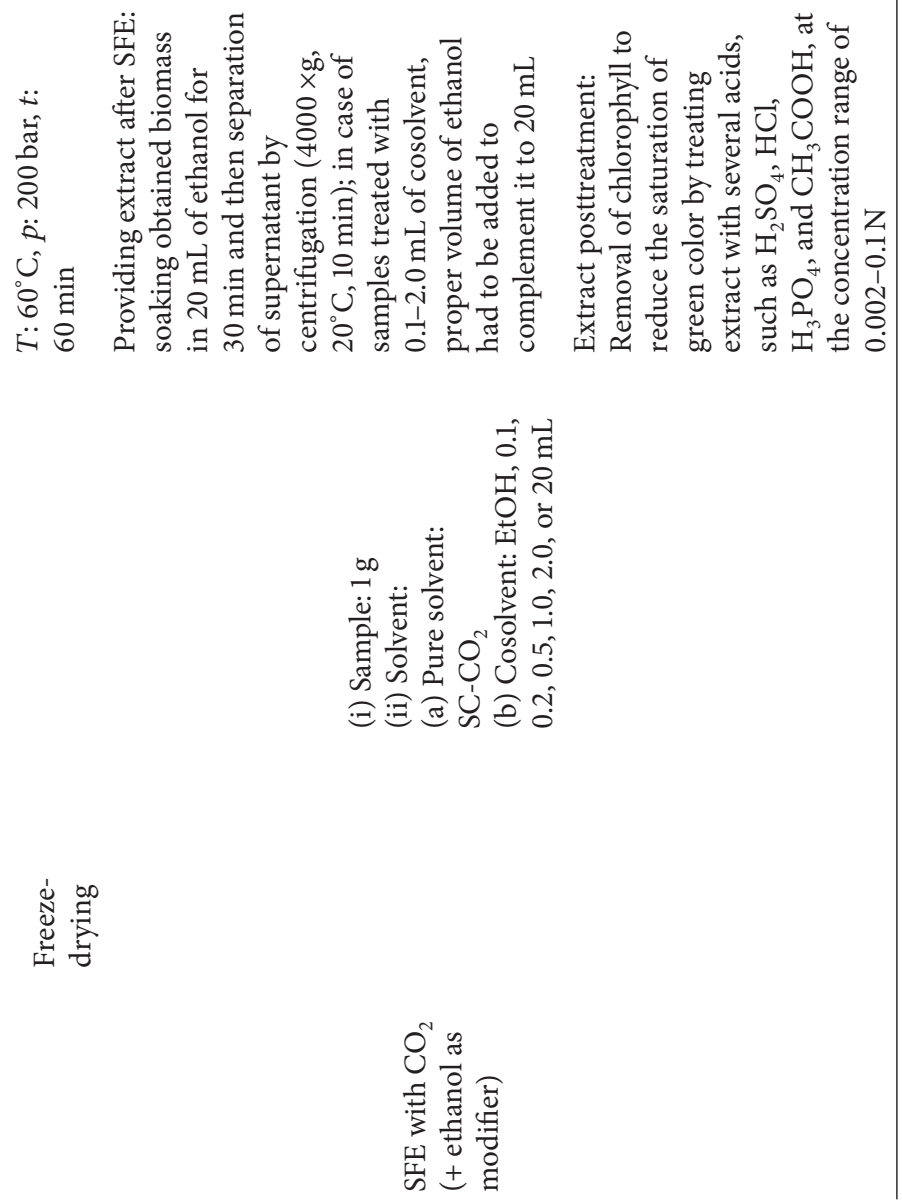


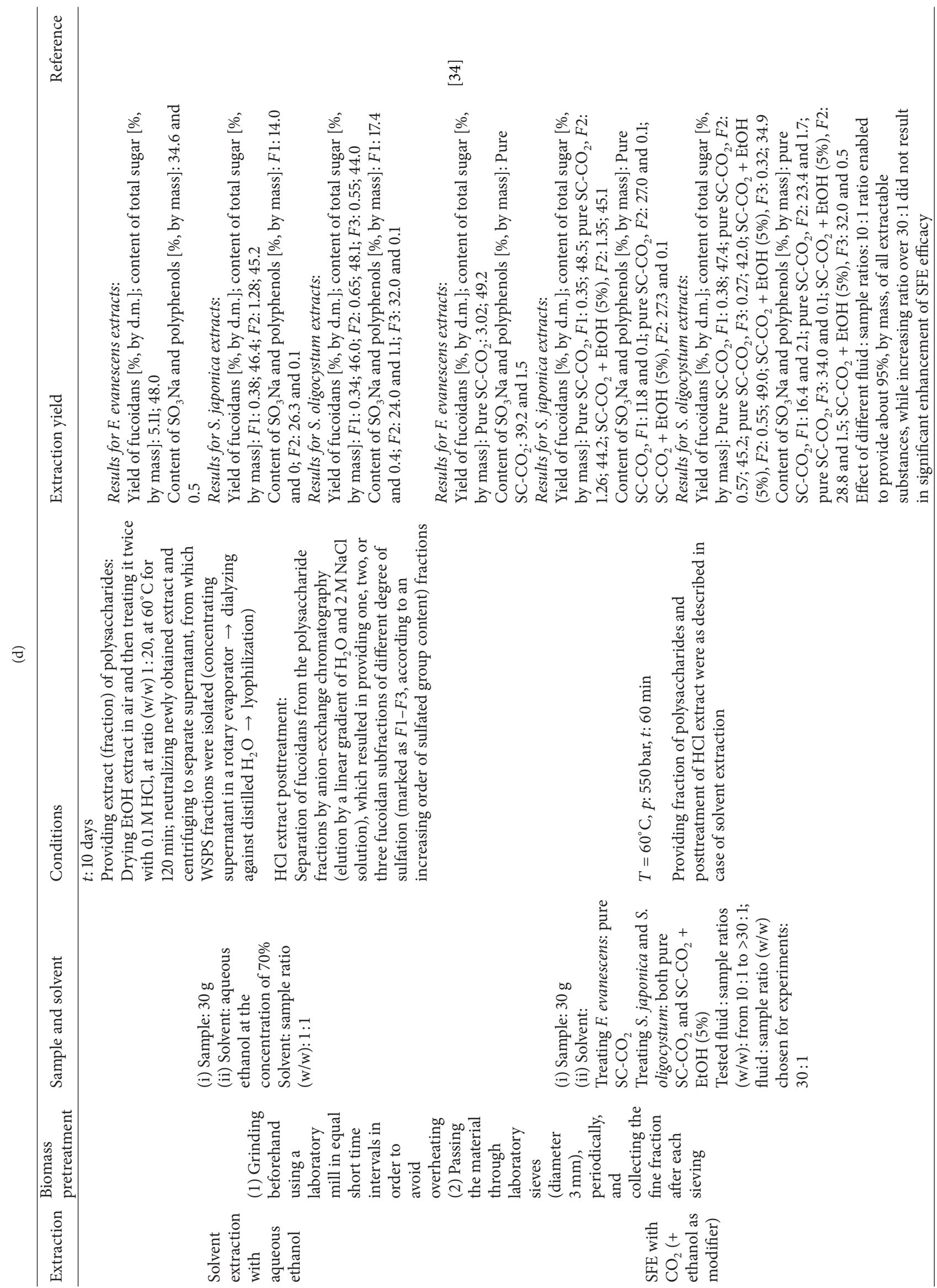


proteins have significant nutritional value to the animal organism [51].

3.4. Algae Based Products in Agriculture. Nowadays, due to future changes in European Union legislations, there is a growing interest in the use of supercritical algal extracts as natural foliar biostimulants for crop production. Plant growth stimulators which are known as phytohormones are the next important group of compounds, which can be extracted from algal biomass by SFE. From a chemical point of view, plant hormones are structurally diverse groups of compounds, which include auxins, gibberellins, cytokinins, salicylic acid, jasmonates, and brassinosteroids [52]. Plant hormones are the promoters of many essential physiological processes such as cell division, growth, and differentiation, organogenesis, sleep and seed germination, aging, and leaves pigments and for the response to biotic stress and abiotic factors $[53,54]$.

The effect induced on plants, by the treatment with products of algal origin, is mainly determined by the content of different types of plant hormones and their concentrations [55]. The functional importance is that these products should be applied in high dilutions. In many bioassays, researchers proved that products made from seaweeds stimulate the growth of many plants. The concentration of used extract and the method of application play an important role in such phenomena. As far as plant hormones and other biologically active compounds affect positively the plants in small concentrations, in higher doses they may cause inhibitory effect on some processes [56].

Algae are also rich in mineral compounds and trace elements. Their role in enhancing the plant growth should be underlined [57]. Möller and Smith investigated the importance of mineral components in suspensions made from seaweeds. Two brown algae extracts were tested on lettuce seedlings. The results showed that extracts were promoting the growth of cotyledon of lettuce. The experiment has led to the conclusion that mineral components were mainly responsible for this effect. Additionally, it was noticed that seaweed suspension was less effective than ashed extract. There is a possibility that suspensions contained some inhibiting organic compounds [58]. Cyanobacteria and eukaryotic algae have also the ability of phosphorus accumulation in the form of polyphosphates which as the reserve of phosphorus can significantly enrich the algal biomass used for the purposes of soil fertility and better plant growth. Seaweed extracts tested on Vigna sinensis stimulated the growth of this plant but only at concentration smaller than $20 \%$. At higher concentration, the effect was the opposite [59]. The use of algal biostimulants may improve seedling growth, shoot and root length and weight, chlorophyll content, and in consequence total protein content. In another bioassay, the information about the influence of seaweed extract on spinach (Spinacia oleracea L.) was presented. Spinach seeds were irrigated with different concentrations of extract from Ascophyllum nodosum. Total flavonoids and phenolic compounds content and antioxidant activity were measured at a certain time after application which confirmed that the use of seaweed extract enhanced all of the tested parameters. Total flavonoids content increased 1.2 and 1.5 times compared to control and the upswing depended on concentration of seaweed extract. Since, total content of phenolic compounds increased, the antioxidant activity also has been improved. The optimal concentration of extract, which showed the desired activity, was determined as $1 \mathrm{~g} / \mathrm{L}[60]$.

Plants treated with algal extracts showed more intense growth of their roots, which significantly improved the uptake of the nutrients from soil. This phenomenon seems to be crucial, especially if regarding the habitats poor in mineral compounds [1]. Field experiment on soybean showed that application of seaweed extract form Kappaphycus alvarezii enhanced yield parameters. Researchers observed also better nutrient uptake by this crop after foliar spraying. The maximum straw yield was obtained after using the extract at a concentration of $15 \%$ [61].

Besides growth promoting effect, seaweed extracts also show antibacterial and antifungal properties. Carrot plants were treated with seaweed extract (0.2\%) from Ascophyllum nodosum $6 \mathrm{~h}$ after the conidial suspension of $A$. radicina or $B$. cinerea was inoculated. After 25 days, the results were measured and the plants treated with seaweed extract exhibited reduced infection by around $50 \%$. Molecular analysis showed the accumulation of defense gene transcripts, phenolics, and phytoalexins [62].

Due to a wide spectrum of positive influence on many aspects of plant growth, several commercially available products derived from algae are being used worldwide. Brown and red algae are the most popular in biofertilizers production, because of their availability throughout all the seasons of the year and high content of bioactive substances. The most known plant growth stimulants manufactured by BASF are Kelpak and Profert, manufactured from Ecklonia maxima and Durvillaea antarctica, respectively. Many manufacturers utilize also brown algae Ascophyllum nodosum for their biostimulating properties [56].

\section{Composition of Algal Extracts: Analytical Methods}

Determination of the full chemical profile of algae is a complicated task, even under unfavorable growth conditions, which significantly enhance the synthesis of active compounds in algal cells. Complexity of the matrix is the major obstacle needed to be overcome.

Furthermore, there are problems in the preparation of biomass samples suitable for the analysis, whereas this pretreatment is the key step in the whole test. This procedure is time consuming and requires several steps including tissue fragmentation (mechanical, using radiation or ultrasounds) and extraction (different types of solvent techniques, supercritical fluid extraction). Algal extract obtained using the above methods needs the specific sample preparation before qualitative and quantitative analysis. The most popular techniques used for this purpose are solid-phase extraction, membrane microextraction, immunoaffinity extraction, vapor-phase extraction, extract filtration, evaporation, and in many cases sample fractionation and derivatization. Working with plants is also hindered considering vulnerability. In 
some conditions, content of chemical compounds might be changing during the extraction and sample preparation. Consequently, the total concentrations of desired compounds might be different compared to the whole plant [63]. A variety of analytical methods are available to determine chemical composition of biological material, depending however on the chemical properties of desired compounds: analytes.

Instrumental methods, combined with various detectors, made it possible to determine several hormones simultaneously in fresh plant material, as well as in products (mostly food) that are used in many bioassays [3, 64-66]. Among these methods, chromatographic techniques seem to be the best and the most accurate for measuring trace amounts of phytohormones in seaweeds and extracts from plants.

Since the early 1970 s of the last century, liquid chromatography and high pressure liquid chromatography have become more popular in plant hormones analysis. Good resolution and relatively low limit of detection allowed for simultaneous qualitative and quantitative determination of various classes of plant hormones [63]. Liquid chromatography used for plant hormone analysis does not require sample derivatization. Popular methods of detection connected with LC or HPLC are UV-V is detectors, diode array and fluorescence detection, and especially MS that allow determining the chemical structure of the analytes [67]. The potential of this method is being multiplied when tandem mass detector is used [68]. Other instrumental methods like capillary electrophoresis or spectral and electrochemical methods and especially biosensors are rather used for the analysis of phytohormones.

For the analysis of nonpolar or volatile compounds from algae extracts, gas chromatography is widely used. This technique, especially combined with mass detectors, is efficient for the structural identification and accurate quantification in multiple phytohormone analysis. Nevertheless, the requirement for sample volatility limits its application to only few plant hormones and potential volatile biostimulants. Sometimes derivatization is needed in case of obtaining better and more reliable results; nevertheless, this step significantly extends the time of analytical procedure [69].

Chromatography assays might be combined with supercritical fluid extraction, resulting in analysis defined as supercritical fluid chromatography (SFC). This method enables performing measurements in automated system under online control, providing shorter time of the assay and decreased level of contamination [70]. Depending on particular need, different ways of collecting SF-extracted analytes might be suitable: (1) solvent collection in a solvent containing vessel, (2) solid-phase collection: highly selective separating analytes on packed-bed column, filled with inert or adsorbing material, from which they are eluted by the use of appropriate solvent, (3) online collection: using a connection of collected device with chromatograph, and (4) alternative collection: (4a) solid-liquid phase collection: recommended for highly volatile analytes, which are trapped in a system of a solidphase and solvent containing vessel (catching losses), (4b) collection inside fused-silica capillaries, and (4c) empty vessel trap collection: a way excluding solvent-sample separation step [71, 72]. Besides the mentioned volatile compounds,
SFC is suitable for testing wide spectrum of molecules with diverse characteristic, for example, polarity and molecular mass, including fat-soluble vitamins (without necessity of former derivatization). In case of algae derived constituents, supercritical fluid chromatography was applied to determine content of isoflavones from seaweeds (brown algae: Sargassum muticum, Sargassum vulgare, and Undaria pinnatifida; red algae: Hypnea spinella, Porphyra sp., Chondrus crispus, and Halopytis incurvus), freshwater green algae (Spongiochloris spongiosa), and cyanobacteria (Scenedesmus and Nostoc 17). The whole experiment involved biomass pretreatment (sonication) and dynamic extraction with $\mathrm{SC}-\mathrm{CO}_{2}$ (modified with aqueous methanol) at $40^{\circ} \mathrm{C}$ and 350 bar for 60 minutes, followed by fast chromatography analysis and tandem mass spectrometry detection [73]. Abrahamsson et al. investigated supercritical fluid chromatography for quantitative determination of carotenoids from microalgae Scenedesmus sp. SFE was performed on pretreated sample (freeze-drying and grinding with liquid nitrogen) using $\mathrm{CO}_{2}$ (with or without co-solvent - ethanol) at flow rate $2 \mathrm{~mL} / \mathrm{min}$, at $60^{\circ} \mathrm{C}$ and 300 bar for 60 minutes, and the obtained extract was analyzed with a series of two columns: C18 and 2-ethyl pyridine. Research proved validation of the method to separate and quantify carotenoids to be comparable to standard approach [74].

\section{Conclusions}

Supercritical fluid extraction gives the possibility to isolate biologically active compounds from the biomass without their degradation. Solvent-free extracts can be used in many branches of industry: as active ingredients in cosmetic products, as components of biostimulant formulations in order to increase crop production, or as feed additive allowing for the production of healthy animal dietary feed supplement. The implementation of new algal-derived products in the market coincides with the public demand for natural products. There is also a need to replace classical extraction methods with innovative technologies based on bioresources. Limited use of environmental friendly $\mathrm{CO}_{2}$ solvent and the possibility of the reuse of waste byproducts produced by SFE are the main advantages of this process, instead of the high costs of the SFE installation. Ingredients derived from raw algal material in SFE process ensure no residues of organic solvents. Therefore, algal extracts have promising future prospects as products for humans, animals, and plants. In this review, special attention was paid to the application of algal extracts in plant cultivation, since this issue is rarely studied in the literature. In order to properly apply algal extract, detailed characteristics should be provided by the use of novel analytical methods.

The potential of algae as the source of many specific substances of biological activity, as well as growing interest and possibilities of using these organisms, creates favorable conditions in many areas of research and development.

\section{Abbreviations}

AA: Arachidonic acid

GLA: $\gamma$-Linolenic acid 
ALA: $\quad \alpha$-Linolenic acid

PLE: $\quad$ Pressurized liquid extraction

AXA: Astaxanthin

PUFA: Polyunsaturated fatty acids

BBE: Bead beater extraction

SCF: $\quad$ Supercritical fluids

DHA: Docosahexaenoic acid

$\mathrm{SC}-\mathrm{CO}_{2}$ : Supercritical carbon dioxide

EPA: Eicosapentaenoic acid

SFC: Supercritical fluid chromatography

FAME: Fatty acid methyl esters

SFE: $\quad$ Supercritical fluid extraction.

\section{Conflict of Interests}

The authors declare that there is no conflict of interests regarding the publication of this paper.

\section{Acknowledgment}

This project is financed in the framework of the grant entitled Innovative Technology of Seaweed Extracts-Components of Fertilizers, Feed, and Cosmetics (PBS/1/A1/2/2012) attributed by The National Centre for Research and Development in Poland.

\section{References}

[1] J. S. Craigie, "Seaweed extract stimuli in plant science and agriculture," Journal of Applied Phycology, vol. 23, no. 3, pp. 371393, 2011.

[2] J. O. Valderrama, M. Perrut, and W. Majewski, "Extraction of astaxantine and phycocyanine from microalgae with supercritical carbon dioxide," Journal of Chemical and Engineering Data, vol. 48 , no. 4 , pp. 827-830, 2003.

[3] S. Gupta and N. Abu-Ghannam, "Recent developments in the application of seaweeds or seaweed extracts as a means for enhancing the safety and quality attributes of foods," Innovative Food Science and Emerging Technologies, vol. 12, no. 4, pp. 600609, 2011.

[4] R. Harun, M. Singh, G. M. Forde, and M. K. Danquah, "Bioprocess engineering of microalgae to produce a variety of consumer products," Renewable and Sustainable Energy Reviews, vol. 14, no. 3, pp. 1037-1047, 2010

[5] J.-L. Pan, H.-M. Wang, C.-Y. Chen, and J.-S. Chang, "Extraction of astaxanthin from Haematococcus pluvialis by supercritical carbon dioxide fluid with ethanol modifier," Engineering in Life Sciences, vol. 12, no. 6, pp. 638-647, 2012.

[6] M. Herrero, J. A. Mendiola, A. Cifuentes, and E. Ibáñez, "Supercritical fluid extraction: recent advances and applications," Journal of Chromatography A, vol. 1217, no. 16, pp. 2495-2511, 2010.

[7] C. Crampon, O. Boutin, and E. Badens, "Supercritical carbon dioxide extraction of molecules of interest from microalgae and seaweeds," Industrial \& Engineering Chemistry Research, vol. 50, no. 15, pp. 8941-8953, 2011.

[8] S. U. Kadam, B. K. Tiwari, and C. P. O’Donnell, "Application of novel extraction technologies for bioactives from marine algae," Journal of Agricultural and Food Chemistry, vol. 61, no. 20, pp. 4667-4675, 2013.
[9] J. B. Hannay and J. Hogarth, "On the solubility of solids in gases," Proceedings of the Royal Society of London A, vol. 30, pp. 324326,1880

[10] K. Zosel, German Patent 1,493,190, 1969.

[11] E. Ramsey, Q. Sun, Z. Zhang, C. Zhang, and W. Gou, "Minireview: green sustainable processes using supercritical fluid carbon dioxide," Journal of Environmental Sciences, vol. 21, no. 6, pp. 720-726, 2009.

[12] P. Mercer and R. E. Armenta, "Developments in oil extraction from microalgae," European Journal of Lipid Science and Technology, vol. 113, no. 5, pp. 539-547, 2011.

[13] Q. Lang and C. M. Wai, "Supercritical fluid extraction in herbal and natural product studies-a practical review," Talanta, vol. 53, no. 4, pp. 771-782, 2001.

[14] M. Herrero, A. Cifuentes, and E. Ibañez, "Sub- and supercritical fluid extraction of functional ingredients from different natural sources: plants, food-by-products, algae and microalgae: a review," Food Chemistry, vol. 98, no. 1, pp. 136-148, 2006.

[15] C. Turner, J. W. King, and L. Mathiasson, "Supercritical fluid extraction and chromatography for fat-soluble vitamin analysis," Journal of Chromatography A, vol. 936, no. 1-2, pp. 215-237, 2001.

[16] J. A. Mendiola, M. Herrero, A. Cifuentes, and E. Ibañez, "Use of compressed fluids for sample preparation: food applications," Journal of Chromatography A, vol. 1152, no. 1-2, pp. 234-246, 2007.

[17] E. Ibáñez, M. Herrero, J. A. Mendiola, and M. Castro-Puyana, "Extraction and characterization of bioactive compounds with health benefits from marine resources: macro and micro algae, cyanobacteria, and invertebrates," in Marine Bioactive Compounds: Sources, Characterization and Applications, M. Hayes, Ed., chapter 2, pp. 55-98, Springer Science+Business Media, New York, NY, USA, 2012

[18] S. Pereda, S. B. Bottini, and E. A. Brignole, "Fundamentals of supercritical fluid technology," in Supercritical Fluid Extraction of Nutraceuticals and Bioactive Compounds, J. L. Martinez, Ed., chapter 1, pp. 1-24, CRC Press, Taylor \& Francis Group, LLC, Boca Raton, Fla, USA, 2008.

[19] D. García-Rodríguez, A. M. Carro-Díaz, and R. A. LorenzoFerreira, "Supercritical fluid extraction of polyhalogenated pollutants from aquaculture and marine environmental samples: a review," Journal of Separation Science, vol. 31, no. 8, pp. 13331345,2008

[20] S. B. Hawthorne and J. W. King, "Principles and practice of analytical SFE," in Practical Supercritical Fluid Chromatography and Extraction, M. Caude and D. Thiebaut, Eds., chapter 6, pp. 219-282, Harwood Academic Publishers, Amsterdam, The Netherlands, 1999.

[21] J. You, W. Lao, and G. Wang, "Analysis of organic pollutants in sewage by supercritical fluid extraction," Chromatographia, vol. 49, no. 7-8, pp. 399-405, 1999

[22] J. Doucha and K. Lívanský, "Influence of processing parameters on disintegration of Chlorella cells in various types of homogenizers," Applied Microbiology and Biotechnology, vol. 81, no. 3, pp. 431-440, 2008.

[23] I. Michalak and K. Chojnacka, "Algal extracts: technology and advances," Engineering in Life Sciences, vol. 14, no. 6, pp. 581-591, 2014.

[24] C. D. Amsler, Ed., Algal Chemical Ecology, Springer, Berlin, Germany, 2009. 
[25] R. L. Mendes, H. L. Fernandes, J. P. Coelho et al., "Supercritical $\mathrm{CO}_{2}$ extraction of carotenoids and other lipids from Chlorella vulgaris," Food Chemistry, vol. 53, no. 1, pp. 99-103, 1995.

[26] R. L. Mendes, B. P. Nobre, M. T. Cardoso, A. P. Pereira, and A. F. Palavra, "Supercritical carbon dioxide extraction of compounds with pharmaceutical importance from microalgae," Inorganica Chimica Acta, vol. 356, pp. 328-334, 2003.

[27] R. L. Mendes, A. D. Reis, A. P. Pereira, M. T. Cardoso, A. F. Palavra, and J. P. Coelho, "Supercritical $\mathrm{CO}_{2}$ extraction of $\gamma$-linolenic acid (GLA) from the cyanobacterium Arthrospira (spirulina) maxima: experiments and modeling," Chemical Engineering Journal, vol. 105, no. 3, pp. 147-152, 2005.

[28] R. L. Mendes, A. D. Reis, and A. F. Palavra, "Supercritical $\mathrm{CO}_{2}$ extraction of $\gamma$-linolenic acid and other lipids from Arthrospira (Spirulina)maxima: comparison with organic solvent extraction," Food Chemistry, vol. 99, no. 1, pp. 57-63, 2006.

[29] P. C. K. Cheung, "Temperature and pressure effects on supercritical carbon dioxide extraction of n-3 fatty acids from red seaweed," Food Chemistry, vol. 65, no. 3, pp. 399-403, 1999.

[30] A. T. Quitain, T. Kai, M. Sasaki, and M. Goto, "Supercritical carbon dioxide extraction of fucoxanthin from Undaria pinnatifida," Journal of Agricultural and Food Chemistry, vol. 61, no. 24, pp. 5792-5797, 2013.

[31] R. Halim, B. Gladman, M. K. Danquah, and P. A. Webley, "Oil extraction from microalgae for biodiesel production," Bioresource Technology, vol. 102, no. 1, pp. 178-185, 2011.

[32] M. O. P. Crespo and M. A. L. Yusty, "Comparison of supercritical fluid extraction and Soxhlet extraction for the determination of PCBs in seaweed samples," Chemosphere, vol. 59, no. 10, pp. 1407-1413, 2005.

[33] K. Fujii, "Process integration of supercritical carbon dioxide extraction and acid treatment for astaxanthin extraction from a vegetative microalga. Short communication," Food and Bioproducts Processing, vol. 90, no. 4, pp. 762-766, 2012.

[34] R. V. Meńshova, F. D. Lepeshkin, S. P. Ermakova, O. I. Pokrovskii, and T. N. Zvyagintseva, "Effect of pretreatment conditions of brown algae by supercritical fluids on yield and structural characteristics of fucoidans," Chemistry of Natural Compounds, vol. 48, no. 6, pp. 923-926, 2013.

[35] W. Kightlinger, K. Chen, A. Pourmir, D. W. Crunkleton, G. L. Price, and T. W. Johannes, "Production and characterization of algae extract from Chlamydomonas reinhardtii," Electronic Journal of Biotechnology, vol. 17, no. 1, pp. 14-18, 2014.

[36] A. Santana, S. Jesus, M. A. Larrayoz, and R. M. Filho, "Supercritical carbon dioxide extraction of algal lipids for the biodiesel production," Procedia Engineering, vol. 42, pp. 1755-1761, 2012.

[37] A. M. F. Palavra, J. P. Coelho, J. G. Barroso et al., "Supercritical carbon dioxide extraction of bioactive compounds from microalgae and volatile oils from aromatic plants," Journal of Supercritical Fluids, vol. 60, pp. 21-27, 2011.

[38] L. Wang, B. Pan, J. Sheng, J. Xu, and Q. Hu, "Antioxidant activity of Spirulina platensis extracts by supercritical carbon dioxide extraction," Food Chemistry, vol. 105, no. 1, pp. 36-41, 2007.

[39] L. Gouveia, B. P. Nobre, F. M. Marcelo et al., "Functional food oil coloured by pigments extracted from microalgae with supercritical $\mathrm{CO}_{2}$," Food Chemistry, vol. 101, no. 2, pp. 717-723, 2007.

[40] P. Thana, S. Machmudah, M. Goto, M. Sasaki, P. Pavasant, and A. Shotipruk, "Response surface methodology to supercritical carbon dioxide extraction of astaxanthin from Haematococcus pluvialis," Bioresource Technology, vol. 99, no. 8, pp. 3110-3115, 2008.
[41] M. G. Sajilata, R. S. Singhal, and M. Y. Kamat, "Supercritical $\mathrm{CO}_{2}$ extraction of $\gamma$-linolenic acid (GLA) from Spirulina platensis ARM 740 using response surface methodology," Journal of Food Engineering, vol. 84, no. 2, pp. 321-326, 2008.

[42] M. D. Macías-Sánchez, C. Mantell, M. Rodríguez, E. M. de la Ossa, L. M. Lubián, and O. Montero, "Supercritical fluid extraction of carotenoids and chlorophyll a from Synechococcus sp.," The Journal of Supercritical Fluids, vol. 39, no. 3, pp. 323329, 2007.

[43] J. A. Mendiola, D. García-Martínez, F. J. Rupérez et al., "Enrichment of vitamin E from Spirulina platensis microalga by SFE," Journal of Supercritical Fluids, vol. 43, no. 3, pp. 484-489, 2008.

[44] M.-T. Golmakani, J. A. Mendiola, K. Rezaei, and E. Ibáñez, "Expanded ethanol with $\mathrm{CO}_{2}$ and pressurized ethyl lactate to obtain fractions enriched in $\gamma$-linolenic acid from Arthrospira platensis (Spirulina)," The Journal of Supercritical Fluids, vol. 62, pp. 109-115, 2012.

[45] P. Bhadury and P. C. Wright, "Exploitation of marine algae: biogenic compounds for potential antifouling applications," Planta, vol. 219, no. 4, pp. 561-578, 2004.

[46] S. Ramesh, R. Rajan, and R. Santhanam, Freshwater Phytopharmaceutical Compounds, CRC Press, Taylor \& Francis, Boca Raton, Fla, USA, 2014.

[47] E. Jin and A. Melis, "Microalgal biotechnology: carotenoid production by the green algae Dunaliella salina," Biotechnology and Bioprocess Engineering, vol. 8, no. 6, pp. 331-337, 2003.

[48] M. Cooney, G. Young, and N. Nagle, "Extraction of bio-oils from microalgae," Separation \& Purification Reviews, vol. 38, no. 4, pp. 291-325, 2009.

[49] J. L. Harwood and I. A. Guschina, "The versatility of algae and their lipid metabolism," Biochimie, vol. 91, no. 6, pp. 679-684, 2009.

[50] A. Sahu, I. Pancha, D. Jain et al., "Fatty acids as biomarkers of microalgae," Phytochemistry, vol. 89, pp. 53-58, 2013.

[51] E. W. Becker, "Micro-algae as a source of protein," Biotechnology Advances, vol. 25, no. 2, pp. 207-210, 2007.

[52] A. Santner, L. I. A. Calderon-Villalobos, and M. Estelle, "Plant hormones are versatile chemical regulators of plant growth," Nature Chemical Biology, vol. 5, no. 5, pp. 301-307, 2009.

[53] V. Gupta, M. Kumar, H. Brahmbhatt, C. R. K. Reddy, A. Seth, and B. Jha, "Simultaneous determination of different endogenetic plant growth regulators in common green seaweeds using dispersive liquid-liquid microextraction method," Plant Physiology and Biochemistry, vol. 49, no. 11, pp. 1259-1263, 2011.

[54] G. Blunden, T. Jenkins, and Y.-W. Liu, "Enhanced leaf chlorophyll levels in plants treated with seaweed extract," Journal of Applied Phycology, vol. 8, no. 6, pp. 535-543, 1996-1997.

[55] H. S. S. Sharma, C. Fleming, C. Selby, J. R. Rao, and T. Martin, "Plant biostimulants: a review on the processing of macroalgae and use of extracts for crop management to reduce abiotic and biotic stresses," Journal of Applied Phycology, vol. 26, no. 1, pp. 465-490, 2014.

[56] W. Khan, U. P. Rayirath, S. Subramanian et al., "Seaweed extracts as biostimulants of plant growth and development," Journal of Plant Growth Regulation, vol. 28, no. 4, pp. 386-399, 2009.

[57] I. J. Crouch and J. van Staden, "Evidence for the presence of plant growth regulators in commercial seaweed products," Plant Growth Regulation, vol. 13, no. 1, pp. 21-29, 1993.

[58] M. Möller and M. L. Smith, "The significance of the mineral component of seaweed suspensions on lettuce (Lactuca sativa L.) seedling growth," Journal of Plant Physiology, vol. 153, no. 56, pp. 658-663, 1998. 
[59] S. Sivasankari, V. Venkatesalu, M. Anantharaj, and M. Chandrasekaran, "Effect of seaweed extracts on the growth and biochemical constituents of Vigna sinensis," Bioresource Technology, vol. 97, no. 14, pp. 1745-1751, 2006.

[60] D. Fan, D. M. Hodges, J. Zhang et al., "Commercial extract of the brown seaweed Ascophyllum nodosum enhances phenolic antioxidant content of spinach (Spinacia oleracea L.) which protects Caenorhabditis elegans against oxidative and thermal stress," Food Chemistry, vol. 124, no. 1, pp. 195-202, 2011.

[61] S. S. Rathore, D. R. Chaudhary, G. N. Boricha et al., "Effect of seaweed extract on the growth, yield and nutrient uptake of soybean (Glycine max) under rainfed conditions," South African Journal of Botany, vol. 75, no. 2, pp. 351-355, 2009.

[62] J. Jayaraj, A. Wan, M. Rahman, and Z. K. Punja, "Seaweed extract reduces foliar fungal diseases on carrot," Crop Protection, vol. 27, no. 10, pp. 1360-1366, 2008.

[63] F. Du, G. Ruan, and H. Liu, "Analytical methods for tracing plant hormones," Analytical and Bioanalytical Chemistry, vol. 403, no. 1, pp. 55-74, 2012.

[64] Y. Wu and B. Hu, "Simultaneous determination of several phytohormones in natural coconut juice by hollow fiber-based liquid-liquid-liquid microextraction-high performance liquid chromatography," Journal of Chromatography A, vol. 1216, no. 45, pp. 7657-7663, 2009.

[65] Y.-H. Li, F. Wei, X.-Y. Dong, J.-H. Peng, S.-Y. Liu, and H. Chen, "Simultaneous analysis of multiple endogenous plant hormones in leaf tissue of oilseed rape by solid-phase extraction coupled with high-performance liquid chromatography-electrospray ionisation tandem mass spectrometry," Phytochemical Analysis, vol. 22, no. 5, pp. 442-449, 2011.

[66] S. Forcat, M. Bennett, J. Mansfield, and M. Grant, "A rapid and robust method for simultaneously measuring changes in the phytohormones ABA, JA and SA in plants following biotic and abiotic stress," Plant Methods, vol. 4, article 16, 2008.

[67] G. L. Gambino, P. Pagano, M. Scordino et al., "Determination of plant hormones in fertilizers by high-performance liquid chromatography with photodiode array detection: method development and single-laboratory validation," Journal of AOAC International, vol. 91, no. 6, pp. 1245-1256, 2008.

[68] M. Müller and S. Munné-Bosch, "Rapid and sensitive hormonal profiling of complex plant samples by liquid chromatography coupled to electrospray ionization tandem mass spectrometry," Plant Methods, vol. 7, article 37, 2011.

[69] Y. Bai, F. Du, Y. Bai, and H. Liu, "Determination strategies of phytohormones: recent advances," Analytical Methods, vol. 2, no. 12, pp. 1867-1873, 2010.

[70] Y. Yang, S. B. Hawthorne, and D. J. Miller, "Comparison of sorbent and solvent trapping after supercritical fluid extraction of volatile petroleum hydrocarbons from soil," Journal of Chromatography A, vol. 699, no. 1-2, pp. 265-276, 1995.

[71] C. Turner, C. S. Eskilsson, and E. Björklund, "Collection in analytical-scale supercritical fluid extraction," Journal of Chromatography A, vol. 947, no. 1, pp. 1-22, 2002.

[72] M. Zougagh, M. Valcárcel, and A. Ríos, "Supercritical fluid extraction: a critical review of its analytical usefulness," TrACTrends in Analytical Chemistry, vol. 23, no. 5, pp. 399-405, 2004.

[73] B. Klejdus, L. Lojková, M. Plaza, M. Šnóblová, and D. Štěrbová, "Hyphenated technique for the extraction and determination of isoflavones in algae: ultrasound-assisted supercritical fluid extraction followed by fast chromatography with tandem mass spectrometry," Journal of Chromatography A, vol. 1217, no. 51, pp. 7956-7965, 2010.
[74] V. Abrahamsson, I. Rodriguez-Meizoso, and C. Turner, "Determination of carotenoids in microalgae using supercritical fluid extraction and chromatography," Journal of Chromatography A, vol. 1250, pp. 63-68, 2012. 

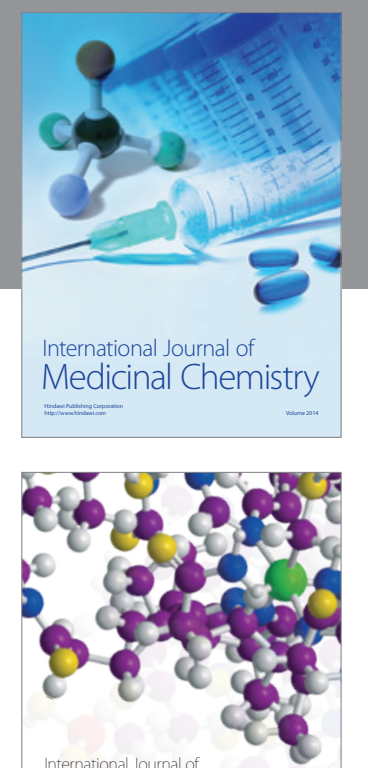

\section{Carbohydrate} Chemistry

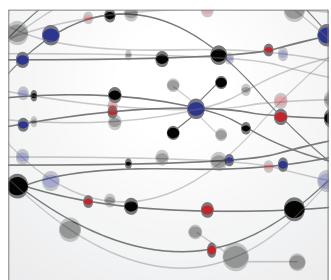

The Scientific World Journal
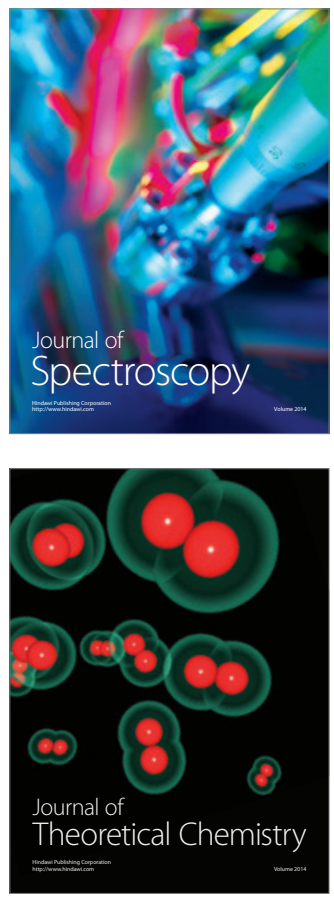
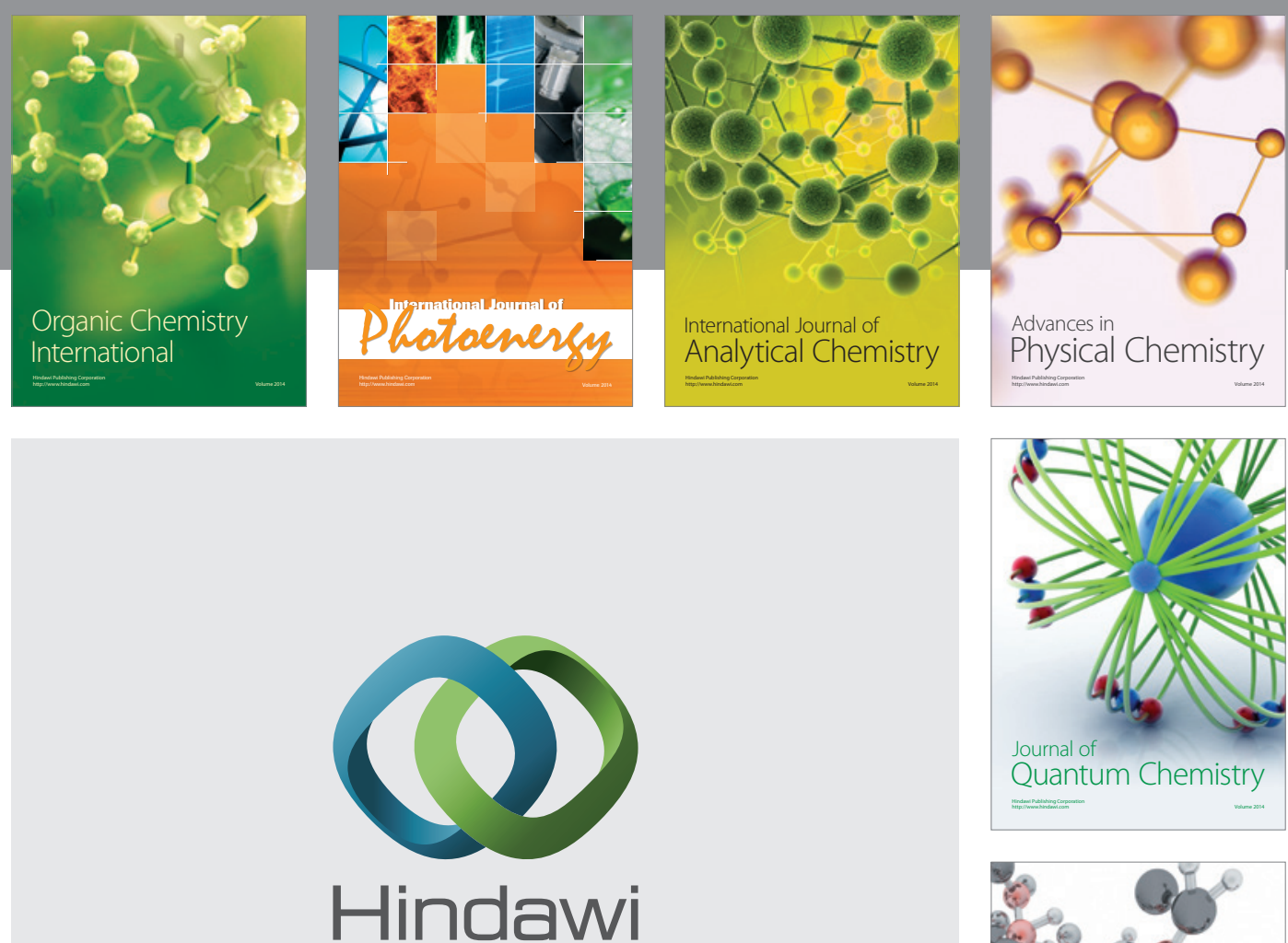

Submit your manuscripts at

http://www.hindawi.com

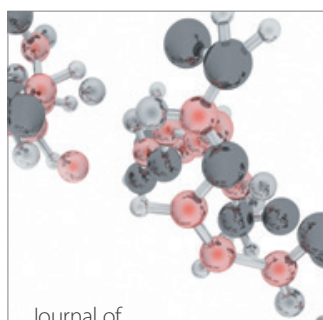

Analytical Methods

in Chemistry

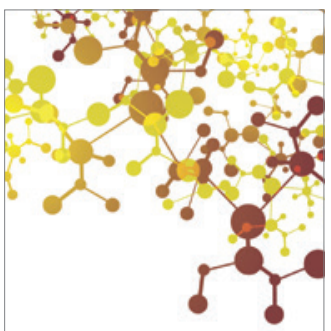

Journal of

Applied Chemistry

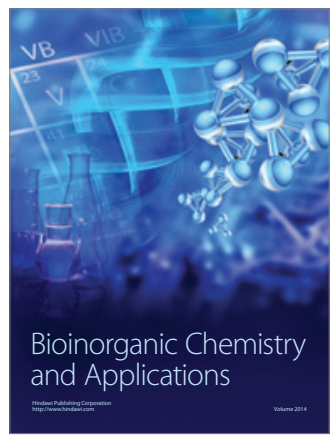

Inorganic Chemistry
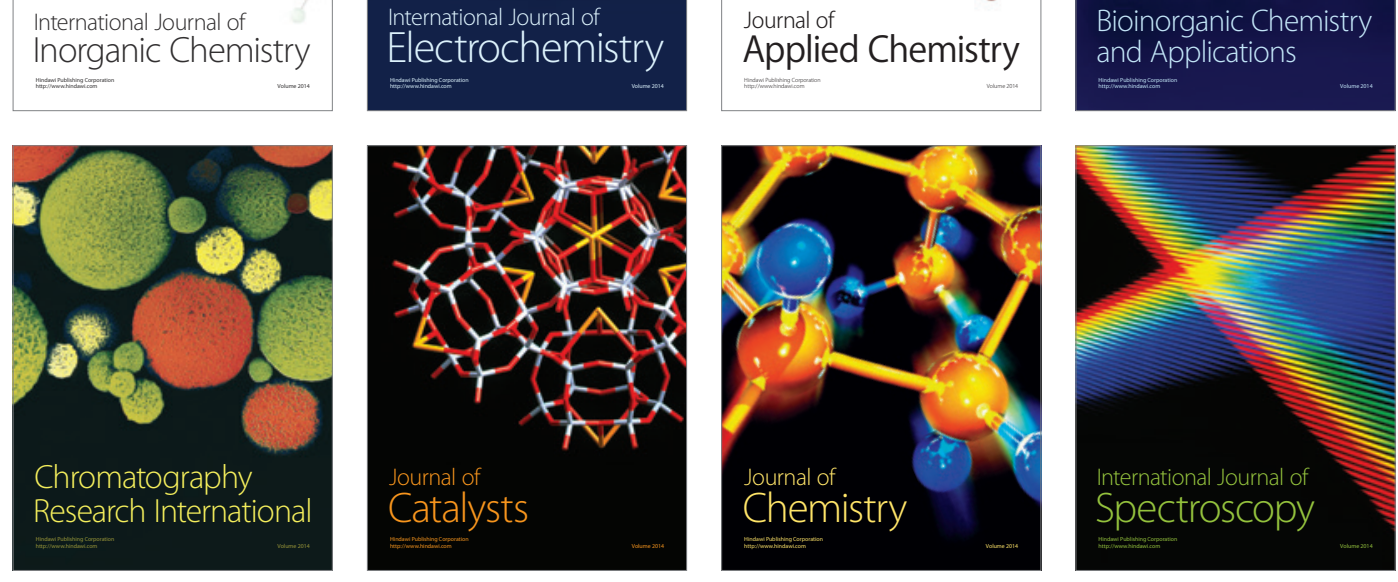